\title{
SAWER PANGANTEN TUNTUNAN HIDUP BERUMAH TANGGA DI KABUpATEN BANDUNG
}

\author{
SAWERPANGANTEN AS FAMILY LIFE GUIDANCE \\ IN BANDUNG REGENCY
}

\author{
Aam Masduki \\ Balai Pelestarian Nilai Budaya Bandung \\ Jln. Cinambo No. 136 Ujungberung - Bandung 40294 \\ e-mail: Masduki.aam@gmail.com
}

\begin{abstract}
Abstrak
Suku bangsa Sunda menghuni hampir seluruh daerah Jawa Barat, satu suku bangsa yang jumlahnya besar. Sebagai satu suku bangsa yang jumlahnya besar, suku bangsa Sunda mempunyai tata cara hidup, adat kebiasaan, dan budaya. Memang terdapat akulturasi dan integrasi dengan kebudayaan lain yang datang dari luar, tetapi masih terdapat hal-hal asli seperti yang kita dapatkan dalam berbagai upacara adat. Upacara adat pernikahan misalnya, upacara ini merupakan warisan adat budaya lama yang masih dilaksanakan di berbagai tempat di Jawa Barat. Sawer (nyawer) adalah salah satu adat kebiasaan pada orang Sunda, yang termasuk ke dalam tata cara upacara adat pernikahan. Kata-kata dalam sawer umumnya mempergunakan bahasa yang sudah biasa dipakai dalam kehidupan sehari-hari, sehingga isi, tema dan amanat mudah dipahami. Sawer perlu diteliti, selain karena merupakan warisan budaya yang mempunyai nilai kerohanian, juga karena puisi sawer merupakan bagian dari khasanah sastra Sunda, yang salah satunya dapat berfungsi sebagai alat pendidikan. Penelitian ini menggunakan metode deskriptif analisis, yakni mendeskripsikan data dan menganalisis data yang dikumpulkan. Hasil pengumpulan data disusun, dianalisis, ditafsirkan, dan dideskripsikan.
\end{abstract}

Kata kunci: sawer panganten, tuntunan hidup, rumah tangga.

\begin{abstract}
Sundanese ethnic groups inhabit almost the entire area of West Java, a large number of ethnic groups. As a large number of ethnic groups, Sunda has the way of life, customs, and culture. Indeed, there are acculturation and integration with other cultures that come from outside, but there are original things like we get from various ceremonies. Customary marriage ceremony, for example, this ceremony is a legacy of the old cultural customs that are still held in various places in West Java. Sawer (nyawer) is one of the customs of the Sundanese people, who belong to the procedures for wedding ceremonies. The words used insawer generally use theterms that are already commonly used in everyday life, so the contents, themes and messages are easy to understand. Sawer need to be investigated, as well as a cultural heritage that has spiritual value, as well as Sawerpoetryis a part of the repertoire of Sundaliterary, one of which can serve as an educational tool. This research uses descriptive method of analysis which describes the data and analyze the collected data. The results of data collectionare compiled, analyzed, interpreted and described.
\end{abstract}

Keywords: sawerpanganten, life guidance, house hold 


\section{A. PENDAHULUAN}

Dalam khazanah budaya bangsa, di berbagai daerah banyak tersebar bentuk sastra lisan,yang antara lain dapat berupa mite, legenda, dongeng, termasuk juga pantun. Cerita-cerita tersebut menurut Yus Rusyana (1981:1) termasuk bentuk sastra lisan karena penyebarannya dalam bentuk tidak tertulis, bersifat anonim, dan disampaikan dengan bahasa mulut. Selain itu, cerita rakyat tidak mempunyai bentuk yang tetap dan memiliki banyak variasi bergantung kepada keahlian bercerita penuturnya.

Keberadaan cerita bentuk sastra lisan dalam kurun waktu sekarang ini ada yang sudah dipublikasikan dan dikenal oleh masyarakat luas, ada pula yang belum dikenal, atau bahkan terdapat di antaranya sastra lisan yang hampir punah.Kondisi demikian memunculkan kekhawatiran putusnya mata rantai kebudayaan di Nusantara.Begitu pula halnya dengan sastra lisan yang berkembang di tatar Sunda yang konon memiliki banyak sastra lisan.

Salah satu bentuk sastra lisan yang berkembang di tatar Sunda adalah jenis sawer.Sastra lisan bentuk sawer ini sebenarnya sudah banyak dikenal oleh penduduk atau masyarakat pada umumnya. sedangkan isi cerita sawer kadang kurang dipahami, apalagi bagi anak-anak usia sekolah masih sulit memahaminya.Padahal dalam tembang sawer ini penuh dengan nasihat sebagai bentuk kepedulian dalam membangun karakter, khususnya dalam berumah tangga.

Kondisi masyarakat dewasa ini sangat memprihatinkan. Perkelahian, pembunuhan, kesenjangan sosial, ketidakadilan, perampokan, korupsi, pelecehan seksual, penipuan, fitnah terjadi di mana-mana. Hal itu dapat diketahui lewat berbagai media cetak atau elektronik, seperti surat kabar, televisi atau internet. Bahkan, tidak jarang kondisi seperti itu dapat disaksikan secara langsung di tengah masyarakat.
Mungkin sudah saatnya kita kembali pada kearifan-kearifan lokal yang terdapat dalam cerita rakyat yang merupakan produk budaya yang luhur.Tidak ada salahnya kalau kita kembali menggali nilai karakter yang ada dalam kearifan lokal itu.

Puisi sawer panganten merupakan salah satu bentuk tradisi lisan dan masuk padawilayah folklore.Istilah folklore di Ind onesiapertama kali dikemukakan oleh James Danandjaja, definisinya adalah sebagai berikut:

"Folklore yaitu sebagian kebudayaan suatu kolektif, yang tersebar dan diwariskan secara turun-temurun, di antara kolektif macam apa saja, secara tradisional dalam versi yang berbeda, baik dalam bentuk lisan maupun contoh yang disertai dengan gerak isyarat atau alat pembantu pengingat” (Danandjaja, 1997:2).

Menurut pendapat Yus Rusyana (1978:1), folklore adalah merupakan bagian dari persendian cerita yang telah lama hidup dalam tradisi suatu masyarakat.

Puisi sawer panganten termasuk ke dalam folklorelisan. Menurut pendapat Yus Rusyana (1976), foklore lisan atau sastra lisan mempunyai kemungkinan untuk berperan sebagai kekayaan budaya khususnya kekayaan sastra; sebagai modal apresiasi sastra sebab sastra lisan telah membimbing anggota masyarakat ke arah apresiasi dan pemahaman gagasan dan peristiwa puitik berdasarkan praktik yang telah menjadi tradisi selama berabad-abad; sebagai dasar komunikasi antara pencipta dan masyarakat dalam arti ciptaan yang berdasarkan sastra lisan akan lebih mudah digauli sebab ada unsurnya yang sudah dikenal oleh masyarakat.

Adapun tujuan yang ingin dicapai melalui penelitian ini di antaranya:(1) Mengetahui struktur teks dari puisi sawer panganten,(2) Mengetahui konteks penuturan puisi sawer panganten,(3) Mengetahui fungsi dan isi dari puisi sawer panganten.

Penelitian Sawer Panganten adat Sunda ini dilakukan sebagai upaya untuk 
mewariskan karya-karya para leluhur kepada generasi muda sehingga dapat melestarikan dan mengembangkan khazanah kehidupan sastra Sunda di tengah-tengah persaingan budaya-budaya lain. Sebab sastra klasik adalah merupakan akar budaya bangsa, cermin jati diri bangsa dan sekaligus merupakan aset bangsa.Bangsa yang tinggi adalah bangsa yang menghargai karya-karya leluhur yang diwariskan kepadanya. Sebagai wujud atas penghargaan tersebut yaitu dengan cara melestarikannya. Banyak cara yang dapat dilakukan untuk melestarikan warisan itu, di antaranya adalah dengan cara mengajarkannya kepada generasi-generasi baru.

\section{B. METODE PENELITIAN}

Adapun metode yang dipergunakan dalam penelitian ini adalah metode deskriptif analisis. Teknik yang dipergunakan dalam pengumpulan data ialah: (1) studi kepustakaan, untuk memeroleh data tentang dasar teoritis yang berhubungan dengan pokok penelitian; (2) wawancara dilaksanakan dengan informan yang dapat memberikan penjelasan tentang sawer; (3) penutur sawer dengan mengutamakan para ahli yang biasa mempergelarkan sawer pada upacara pernikahan.

\section{HASIL DAN BAHASAN}

Upacara sawer panganten mempergunakan bahasa sebagai alatnya. Menurut R. Satjadibrata dalam Kamus Umum Basa Sunda (1954) istilah sawer itu mempunyai dua arti yaitu:

1. Sawer artinya air hujan yang masuk ke rumah karena terhembus angin (tempias); kasaweran, kena tempias; panyaweran, tempat jatuhnya air dari bubungan (taweuran).

2. Sawer (nyawer), menabur (pengantin) dengan beras dicampur uang tektek (lipatan sirih), dan irisan kunir.

Menurut Kamus Umum Basa Sunda yang dikeluarkan oleh Lembaga Basa dan
Sastra Sunda, sawer berarti petuah untuk pengantin dalam bentuk syair, diiringi dengan tembang berisi nasihat orang tua (Yetty Kusmiaty Hadish,1986:11).

Sawer merupakan suatu tradisi dari nenek moyang orang Sunda secara turun temurun ketika seseorang memiliki hajatan pernikahan anaknya. Isi sawer merupakan pepatah dari orang tua kepada anaknya yang akan menjalani kehidupan baru, yakni berumah tangga. Pepatah sawer tersebut biasanya disampaikan atau dituturkan oleh juru sawer. Isi sawer berupa tuntunan berumah tangga, ajaran keagamaan, dan ajaran sopan santun antara suami istri.

Bahan dan alat-alat yang digunakan dalam upacara saweran adalah sebagai berikut :

1. Beras putih, simbol atau maknanya adalah:

Ketentraman dalam sebuah keluarga salah satu syaratnya adalah cadangan pangan yang aman. Untuk masyarakat Sunda cadangan pangan yang pertama dan utama adalah padi atau beras. Bila telah meraih itu semua, keluarga Sunda tersebut dengan sendirinya akan merasakan seperti apa yang terungkap dalam peribahasa sapapait samamanis, dan akhirnya akan tercipta ketenangan dalam rumah tangga.

2. Leupit, simbol atau maknanya adalah :

Leupit adalah sirih yang dilipat segi tiga, di dalamnya berisi seperti kapur sirih, gambir, pinang, kapol, saga, dan tembakau. Leupit mempunyai makna kehidupan dalam rumah tangga harus terbuka baik suami terhadap isteri maupun sebaliknya, Maksud terbuka di sini adalah penghasilan dari hasil pekerjaan masing-masing harus saling diketahui. Sedang rasa leupit kalau dikunyah ada rasa pahit, manis, melambangkan bahwa menjalani rumah tangga tidak selalu manis dan pahit. 
3. Kunyit, simbol atau maknanya adalah:

Kunyit adalah bumbu dapur yang berwarna kuning. Kuning adalah lambang dari emas. Maksudnya, supaya rumah tangga calon pengantin dihargai oleh orang lain. Seperti kita yang menghargai mahalnya nilai emas.

4. Uang logam, makna atau simbol dari uang logam adalah :

Uang logam (uang receh) adalah lambang dunia atau kekayaan. Hidup di dunia harus mempunyai semangat. Oleh karena itu, mencari kekayaan dalam wujud materi seperti kita akan hidup di dunia untuk selamanya, serta menyiapkan bekal akhirat seperti kita akan mati hari esok.

5. Permen simbol atau maknanya adalah:

Umumnya rasa permen adalah manis. Oleh karena itu dalam rumah tangga harus diwarnai oleh memanis atau didasari keharmonisan keluarga yang luwes, tidak monoton, penuh inovasi, dan fungsi keluarga sesuai dengan harapan, yaitu menggapai kebahagian. Caranya antara suami dan istri saling menyayangi, tidak gampang tersulut nafsu. Bahkan, bila perlu lebih baik mengalah ketimbang menyemai bibit pertikaian.

Sebelum upacara nyawer dilaksanakan, terlebih dahulu disiapkan kursi untuk duduk kedua pengantin, dan satu orang ditugaskan untuk memegang payung. Payung digunakan untuk melindungi kepala kedua pengantin dari barang-barang saweran yang bertaburan.

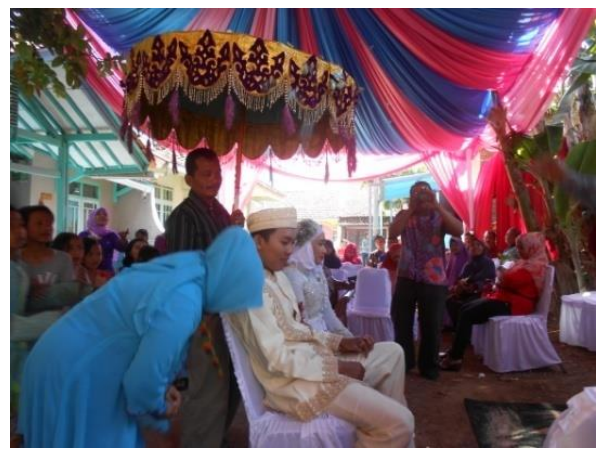

Gambar 1. Panganten sedang Dipayungi Sumber: Aam Masduki, 2015.

Payung ini berwarna kuning disebut payung agung dan mempunyai makna. Maknanya adalah kedua pengantin diharapkan dapat menjadi pengayom atau jadi pelindung bagi orang lain.

Selanjutnya juru sawer menyiapkan bahan-bahan dan alat-alat saweran. Kemudian mempersilahkan pengantin untuk duduk di kursi yang sudah disiapkan dan disaksikan oleh kedua belah pihak orang tuanya. Juru sawer menerangkan makna dan tujuan dari pelaksanaan upacara saweran. Sebelum upacara nyawer dimulai terlebih dahulu juru sawer memanjatkan doa agar mendapat ridho dari Tuhan Yang Maha Esa.

Naskah sawer panganten di Desa Hegarmanah, Kecamatan Cikancung, Kabupaten Bandung pada umumnya terdiri atas tiga bagian: (1) pembuka, (2) isi, dan (3) penutup. Apabila kita kaji, di setiap bagian naskah sawer panganten, kita dapat menemukan berbagai macam nilai yang bisa kita aplikasikan dalam hidup. Setiap bagian dari sawer panganten memiliki penuturan yang khas sesuai dengan nilai yang terkandungnya seperti kutipan dibawah ini. 


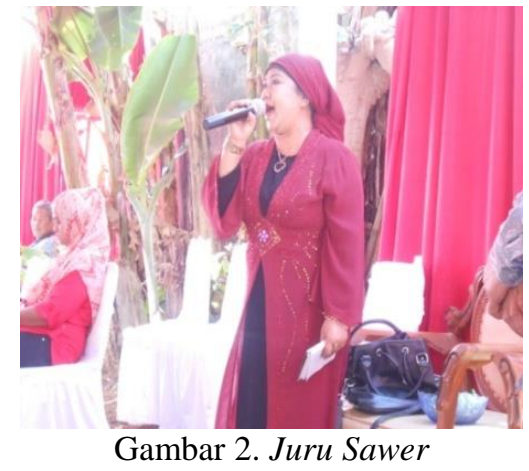

Sumber: Aam Masduki, 2015.

a. Nilai Ketuhanan/Keagamaan

1) Pembuka :

Bismillah ngawitan ngidung

Bismillah memulai nyanyian

Nyebat asma Maha Suci

Menyebut nama Maha Suci

Maha Welas, Maha Asih

Maha Pengasih, Maha Penyayang

Cunduk waktu nurhayu

Tiba saatnya kebahagiaan

Niti wanci nu mastari

Meniti waktu yang pasti

Hidep nalikeun duriat

Kalian mengikat cinta kasih

Ngaitkeun asih birahi

Menyatukan kasih sayang

Tumut parentah Pangeran

Mengikuti perintah Allah

Gusti nu Maha Kawasa

Allah yang Maha Kuasa

$N u$ munajat siang wengi

Tempat meminta siang malam

Sangkan kang putra waluya

Agar sang putra mendapat kemuliaan

Siang pinareng wengi

Siang dan malam
Prung anaking geura manggung

Segeralah anakku laksanakan

Didoakeun beurang peuting

Didoakan siang dan malam

Geus tandang cumarita

Sudah tiba saatnya

Neneda ka Maha Suci

Memohonlah kepada yang Maha Suci

Ginanjar kawilujengan

Agar mendapat keselamatan

Amin ya robbal allamin

Amin ya robbal allamin

Mugi Gusti nangtayungan

Semoga Allah melindunginya.

2) Isi :

(a) Ya Allah Nu Maha Agung

Neda welas asih Gusti

Dilelerkeun ka pun anak

$\mathrm{Nu}$ kiwari nitih wanci

Dahup bada diakadan

jadi laki rabi

Terjemahan:

Ya Allah yang Maha Agung

Mohon pengasih dari-Mu

Tercurah pada anakku

Yang sekarang memasuki

Bersatu resmi menikah

Menjadi suami istri

Neneda ka Maha Agug

Muntang ngeumbing ka Yang Widi

Hirup sing gede bagjana

Sing soleh sarta walagri

Jauh tina panaca bahla

Hirup hurip nu utami

Terjemahan:

Memohon pada Yang Agung

Berpegang pada Yang Widi

Semoga saleh dan selamat

Dijauhkan dari bahaya 
Hidup senang sepantasnya

Ganjaran ti Maha Suci

Enggal atuh geura tampi

Ayeuna eulis ngahiji

Sakapeurih sakanyeri.

Terjemahan :

Pahala dari Tuhan Yang Maha Suci

Cepatlah segera terima

Sekarang kamu bersatu

Seia sekata dalam suka dan duka

Pertikahan eta sumpah

Ditalian ku sahadat

Ulah rek di mumurah

Ulah nikah ngumbar napsu

Lamun geus mimiti layu

Oncomeos cala-culu

Terjemahan :

Pernikahan itu sumpah

Terikat dengan sahadat Janganlah dianggap murah

Menikah karena nafsu

Jika sudah dimulai

Bersenang-senang tak menentu

Ulah nyaah sabot geulis

Diilo dieulis-eulis

Jadi murag bulu bitis

Ulah melang sabot monyas

Lamun geus pias koneas

Sigana sagala luas

Terjemahan:

Jangan sayang saat cantik

Disanjung dengan sebutan eulis

Lalu tak senang di rumah

Jangan sudah pucat pasi

Tampaknya serba berani

(b) Lugina dunya aherat

Gusti maparinan rahmat

Kana waktu ulah elat

Disarengan silih hormat

Terjemahan :

Bahagia dunia akhirat

Tuhan memberikan rahmat

Pada waktu jangan lupa

Diikuti saling menghormati (c) Silih hormat ka sasama Sing nyaah ka ibu rama Lakonan parentah agama Tangtuna hirup sugema

Terjemahan :

Saling hormat kepada sesama

Supaya kasih sayang kepada orangtua Lakukan perintah agama

Niscaya hidup bahagia

Anyaran mah sarareungit

Lila-lila bau hagit

Rabig jadi enggon reungit

Anyaran madep satia

Lila-lila bet sulaya

Ka caroge sua-sia

Terjemahan:

Pada mulanya serba harum

Lama kelamaan berbau angit

Rambut dan pakaian

Merupakan sarang nyamuk

Pada mulanya patuh setia

Lama kelamaan berubah

Terhadap suami tak sopan

Anyaran mah engkang agan

Lila-lila bet ogoan

Ka caroge nyanggerengan

Tetenjrag jeung molototan

Tutunjuk bari nyarekan

Nyingsat jeung abret-abretan

Terjemahan :

Pada mulanya engkang

Agak lama kelamaan menjadi

Tinggi hati, terhadap suami melawan

Kasar dan berani buka mata, main

Tunjuk memarahi, marah berperilaku tidak wajar.

Urang cukupkeun sakieu

Geura pek geura sayagi

Beber layar jait jangkar

Ngambah samudra rarabi

Bapa jeung ema gugupay

Ngadua sisi basisir

Terjemahan: 
Kita cukupkan sekian

Kini kau bersedialah

Untuk kau pergi berlayar

Mengarungi samudra kehidupan

Ayah bundamu melambai

Di tepi pantai mendoa

Siloka sawer karuhun

Koneng diawur ku koneng

Beas diawur ku beas

Duit diawur ku duit

Moal kurang sandang pangan

Pibekeleun hirup hurip

Terjemahan:

Seloka sawer leluhur

Kunir tabur dengan kunir

Beras ditabur dengan beras

Uang ditabur dengan uang

Takkan kurang sandang pangan

Untuk bekal hidup makmur

Dari tiga bait isi di atas terungkap gagasan-gagasan pokok yang berkaitan dengan tema ketuhanan/keagamaan. Bait (1) mengungkap persoalan bahwa segala perbuatan yang dilakukan manusia di dunia ini niscaya akan mendapatkan ganjaran yang setimpal dari Allah SWT. Bait (2) mengungkap persoalan bahwa dalam kehidupan di dunia manusia jangan melupakan kewajiban salat agar hidupnya mendapatkan rahmat. Demikian juga pada bait (3) yang mengungkap persoalan bahwa agar hidup di dunia sempurna, kita jangan lupa menjalankan perintah agama dan selalu hormat kepada orangtua serta sesama insan. Persoalan-persoalan tersebut berkaitan dengan aspek-aspek ajaran keagamaan/ketuhanan dan menjadi gagasan pokok yang dibicarakan dalam bait sawer tersebut.

\section{b. Nilai Budi Pekerti/Moral}

1) Tigin eulis kumawula

Ka raka ulah baha

Bisi raka meunang bahla

Kudu bisa silih bela

Terjemahan:

Setia kamu meladeni/mengurus
Kepada suami jangan menentang

Nanti suami mendapat celaka

Harus dapat saling membela

Jodona sing panjang punjung

Silih asah silih asih

Bagja mulya rumah tangga

Ti lahir dugi ka batin

pinareng kasalametan

parek rizki jauh balai

Terjemahan :

Jodohmu semoga panjang

Saling asuh saling mengasihi

Bahagia rumah tangga

Dari lahir hingga batin

Jauh dari godaan dan banyak rezeki

Poma ulah rek adigung

Ka sasama hiri dengki

Tinangtu engke ahirna

Berewit lampahing ati

Dibeakkeun ku sasama

Hirup tinggal nu mandiri

Terjemahan :

Janganlah kalian sombong

Berhati jahat dan dengki

Sebab pasti akan berakhir

Dengan sangat merugi

Ditinggalkan kawan-kawan

Akhirnya hidup sendiri

2) Jodona sing lambat lambut

Soleh ati luhung budi

Sing jadi warga masarakat

Anu asih ka nu miskin

Anu nyaah ka sasama

Nu bakti ka kadang warga

Terjemahan :

Selamat perjodohanmu

Hidup berbudi tinggi

Menjadi warga masyarakat

Yang mengasihi si miskin

Dan sesama manusia

Berbakti pada yang lain

Mugi-mugi panjang punjung

Panjang suka panjang asih

Panjang jodo duriatna

Rapih sakulah sakolih

Runtut raut saaleutan 
Jatnika lahir tur batin

Terjemahan:

Semoga rumah tanggamu

Abadi hingga akhir hayat

Hidup seiring sejalan

Bahagia lahir batin

3) Mun akur ka sadayana

Tembongkeun budi basana

$\mathrm{Nu}$ bener tingkah polahna

Supaya hirup sampurna

Terjemahan:

Kalau rukun kepada semuanya

Perlihatkan budi bahasanya

Yang benar tingkah lakunya

Supaya hidup sempurna

Mungguh rumah tangga tangtu

Lir kapal jero jaladri

Garwa minangka layarna

Carogé lir juru mudi

Di lautan satujuan

Sapapait samamanis

Guguru ka lauk laut

Sanajan caina asin

Awakna teu katépaan

Mandiri dina pribadi

Mangpaat keur nu lian

Jadi pamungpungan asih

Artinya:

Rumah tangga yang sebenarnya

Seperti kapal dalam samudra

Istri sebagai layarnya

Suami seperti nakhoda

Di lautan satu tujuan

Sepahit semanis (harmonis dalam hidup)

Berguru kepada ikan di laut

Walau airnya asin

Badannya tidak tertular (asin)

Mandiri dalam pribadi

Manfaat untuk yang lain

Jadi tempat berkasih sayang

Mugi-mugi Yang Agung

Ka Gusti Nu Maha Suci

Ka Yang Sukma Jati Mulya

Anu sipat Rohman Rahim
Mugi kersa nangtayungan

Ka panganten jaler istri

Terjemahan:

Semoga kepada Yang Agung

Kepada Tuhan Yang Maha Suci

Kepada yang sukma jati mulya

Yang bersifat rakhman rakhim

Semoga melindungi

Kepada pengantin suami istri

Ginanjar kawilujengan

Panjang punjung sinugengan

Lulus taya kakurangan

Rakhmat Gusti pinarengan

Panjang pujung panjang yuswa

Amin Ya Robbal Alamin

Mugi Gusti nangtayungan

Terjemahan :

Diberi keselamatan

Sejahtera selamanya

Baik tanpa kekurangan

Disertai rakhmat Tuhan

Selamat dan panjang umur

Amin Ya Robbal Alamin

Semoga Tuhan melindungi kita semua.

Dari bait-bait di atas terungkap gagasan-gagasan pokok tentang budi pekerti/moral. Bait (1) mengungkap persoalan bahwa dalam berumah tangga keduanya (istri dan suami) harus setia terhadap janji dan juga harus saling membela jika berada dalam kesulitan. Bait (2) mengungkap persoalan bahwa dalam kehidupan sehari-hari di rumah tangga harus selalu menunjukkan budi pekerti yang luhur. Demikian juga pada bait (3) yang mengungkap persoalan bahwa agar hidup di dunia sempurna kita harus selalu menunjukkan tingkah laku dan berbahasa yang sopan agar hidup tentram dan nyaman. Persoalan-persoalan tersebut berkaitan dengan aspek-aspek ajaran budi pekerti/moral dan menjadi gagasan pokok yang dibicarakan dalam bait sawer tersebut. 


\section{c. Nilai Kecerdasan}

Nilai kecerdasan dapat diartikan sebagai ukuran tingkah laku manusia tentang kepandaian dan ketajaman pikiran yang harus dipertahankan dalam pola kehidupan bermasyarakat. Berikut ini baitbait sawer yang mengandung nilai didaktis aspek kecerdasan :

1) Gusti Allah nu kawasa

Ngayakeun dunya tiasa

Pepek eusi dunya rosa

Sayagi pikeun manusa

Terjemahan :

Gusti Allah yang berkuasa

Mengadakan dunia bisa

Dengan segala isi dunia

Disediakan buat manusia

2) Manusa mahluk punjulna

Pinter pangabisana

Ngakalan eusi dunyana

$\mathrm{Nu}$ kantun tumarimana

Terjemahan :

Manusia makhluk tertinggi

Pintar ilmu pengetahuan

Memikirkan isi dunia

Yang tinggal hanya berterimanya

Dari dua bait sawer di atas dapat terungkap nilai-nilai didaktis yang berkaitan dengan aspek kecerdasan. Pada bait (1) terungkap bahwa Allah yang Maha Kuasa menciptakan alam dunia ini dengan segala isinya yang diperuntukkan bagi umat manusia. Untuk memanfaatkannya maka manusia harus mampu mengolah dan memanfaatkan dengan kecerdasan dan ilmu pengetahuan yang dianugrahkan Allah kepada manusia. Demikian juga pada bait (2) terungkap sebuah nilai kecerdasan yaitu bahwa manusia diberi akal pikiran yang lebih jika dibandingkan dengan makhluk lainnya di dunia ini. Oleh karena itulah manusia harus mampu menggunakan akal kelebihannya itu untuk kehidupan di dunia.

Berdasarkan analisis tersebut dapat disimpulkan bahwa dalam naskah sawer pengantin terdapat nilai-nilai didaktis yang berkaitan dengan aspek kecerdasan, yaitu nilai-nilai yang berkaitan dengan bagaimana ukuran tingkah laku manusia dalam menggunakan kepandaian dan ketajaman pikiran dalam menjalani kehidupan di masyarakat.

\section{d. Nilai Ilmiah}

Nilai ilmiah dapat diartikan sebagai ukuran tingkah laku manusia tentang berpikir yang didasarkan ilmu pengetahuan yang harus dipertahankan dalam kehidupan di masyarakat. Sebagai gambaran nilai-nilai ilmiah dalam naskah Sawer Penganten dapat dilihat pada bait sawer berikut ini.

1) Mun catur sing seueur bukur Ulah ngan kalah ka saur Napsuna ulah takabur Hirup resep loba batur

Terjemahan :

Kalau bicara banyak nyata Jangan hanya bicara saja Nafsunya jangan sombong Hidup suka banyak teman

Laki rabi teh mandiri Sagala kuma sorangan Hidep teh masing rancage Sadar sabar jeung tawekal Ihtiar keur modalna Repeh rapih reujeung batur Sok komo urang jeung urang

Terjemahan:

Berumah tangga itu mandiri

Tergantung diri pribadi

Hendaklah kau berusaha

Sadar sabar bertawakal

Berikhtiar untuk modal

Seia dengan sesama

Apalagi dengan kawan

Ngambah jagat pawenangan

Kudu nambahan pangarti

Lengkah keur nambahan luang

Ajirna diri pribadi

Sangkan kuat lahir batin

Hirup ajeg laur tangtung

Kitu kuduna manusa

Kudu ngarti jeung kaharti 
Sangkan bisa nepungkeun

Aing jeung urang

Terjemahan:

Hidup di alam dunia

Hendaknya menambah ilmu

Yang dicari pengalaman

Tandanya diri pribadi

Agar kuat lahir batin

Teguh tegak pendirian

Demikian hendaknya manusia

Harus paham dan dipahami

Agar bisa mempertemukan aku dan dirinya

2) Boga rasa kudu ngarti

Tata titi surti ati

Kudu silih beuli ati

Pikiran dadamelan gusti

Terjemahan :

Punya rasa harus mengerti

Prilaku mawas diri

Harus saling menyenangkan hati

Ingatkan ciptaan Tuhan

Dari dua bait sawer di atas terungkap nilai-nilai didaktis yang berkaitan dengan aspek ilmiah, yaitu bagaimana manusia bisa berpikir tentang kehidupan bermasyarakat yang didasarkan pada konsep ilmu pengetahuan. Pada bait (1) terungkap sebuah nilai keilmuan yaitu bahwa dalam kehidupan bermasyarakat jangan hanya pintar berbicara tetapi harus dibuktikan dengan hasil pekerjaan yang tentu saja memerlukan ilmu pengetahuan. Demikian pula halnya, pada bait (2) terungkap sebuah nilai keilmuan yaitu bahwa manusia sebagai ciptaan Tuhan harus mampu menggunakan ilmu pengetahuannya untuk mengolah segala sesuatu di sekeliling kehidupannya.

Berdasarkan bait sawer di atas dapat disimpulkan bahwa dalam naskah Sawer Panganten terdapat nilai-nilai didaktis yang berkaitan dengan aspek keilmuan, yaitu nilai-nilai yang berkaitan dengan bagaimana ukuran tingkah laku manusia dalam berpikir yang didasarkan ilmu pengetahuan yang harus dipertahankan dalam kehidupan di masyarakat.
Selain keempat nilai yang terkandung dalam naskah Sawer Panganten di atas, masih terdapat nilai-nilai lain yang bisa kita kaji dan diaplikasikan dalam pendidikan karakter. Hanya kemauan kitalah yang biasanya menjadi tantangan terbesar dalam menggali nilai-nilai tersebut.

Puisi sawerpanganten ditembangkan oleh dua orang penembang laki-laki dan perempuan, disebut juga dengan juru sawer. Dalam acara tersebut juru sawer panganten ditemani juru rias pengantin dan orang tua dari kedua mempelai yang biasanya hanya diwakili olah para ibunya. Pada saat itu, juru rias terkadang ikut nyawer dengan menembangkan puisi sawer panganten. Pada saat acara, penembang membawa catatan yang digunakan hanya sebagai pengingat kalaukalau penembang lupa. Hal tersebut terjadi, karena penembang atau juru sawer sudah hafal teks tembang puisi sawer panganten, disebabkan telah sering menembangkan.

Peran penembang atau juru sawer puisi sawer panganten adalah sebagai pencipta juga pemilik, artinya selain memiliki teks turunan, juga sebagai pencipta teks yang baru. Akan tetapi, dalam menciptakan teks yang baru, biasanya hal itu dilakukan hanya untuk kepentingan dirinya sendiri.

Fungsi dan tugas juru sawer dalam acara saweran adalah berperan sebagai orang tua pengantin. Kesan yang ditimbulkan ketika juru sawer menembangkan puisi sawer panganten pada saat acara saweran, seakan menjadi orang tua yang sedang memberikan nasihat kepada anaknya yang hendak menjalani kehidupan baru atau berumah tangga. Setelah selesai, selesai pula tugas dan fungsi penembang. Tugas tersebut ditentukan dari selesainya suatu teks ditembangkan.

Orang yang hadir dalam acara sawer panganten atau saweran, cukup beragam, mulai dari anak-anak sampai orang tua. Rata-rata mereka yang hadir berasal dari 
daerah setempat yang merupakan tetangga dekat dari penyelenggara hajatan.

Pada acara tersebut, khalayak berdiri di depan penembang yang pada awal penembangan mereka diam tidak bersuara. Namun, ketika tembang sawer panganten sudah dimulai mereka terdengar ribut kembali apalagi setelah tembang berlangsung beberapa menit, mereka sudah mulai kesal yang ditandai dengan adanya ungkapan wuur...wuur...wuur... Kata tersebut, ditujukan sebagi salah satu cara yang dipakai supaya penembang segera menyawerkan uang yang dari awal telah dipegang oleh penyelenggara hajatan. Kata itu juga implisit mengandung makna supaya penembang segera mengakhiri tembangannya.

Anak-anak yang hadir dalam acara tersebut bercampur antara laki-laki dan perempuan. Sementara untuk para orang tua biasanya didominasi oleh para ibu. Dalam acara itu mereka seakan menjadi satu, tidak ada anak-anak ataupun orang tua, mereka bersaing untuk mendapatkan saweran. Ketika saweran dilemparkan mereka saling berebut. Akan halnya untuk pemahaman terhadap isi uraian dari tembang puisi sawer panganten yang disajikan, sama sekali tidak terlihat apabila mereka memerhatikan uraiannya. Motifasi mereka berada di tempat tersebut yaitu untuk mendapatkan saweran yang berupa uang maupun permen. Seiring dengan perkembangan zaman yang sudah semakin maju, kini saweran ada yang berupa sebuah undian yang dapat ditukar dengan barang-barang elekrtonik atau barangbarang lainnya.

Dengan demikian acara saweran sesugguhnya hanya dianggap sebagai bahan hiburan saja.Apabila diamati secara cermat rasanya hanya sebagian orang tua yang memperhatikan pada isi uraian dari tembang puisi sawer panganten tersebut.

Interaksi yang terjadi antara penembang dengan para hadirin dalam penembangan tembang puisi sawer panganten salah satunya dapat diketahui melalui tuturan yang dilontarkan oleh para hadirin yaitu kata wuur...wuur...wuur.... wuuurr.

Kata "wuur" dapat menunjukkan sebagai salah satu bentuk interaksi karena dari kata tersebut, juru sawer mengetahui apabila para hadirin sudah mulai jenuh atau bosan dan menginginkan supaya juru sawer mengakhiri puisi sawer panganten yang ditembangkannya.

Interaksi tersebut bukan merupakan suatu interaksi yang akan memacu juru sawer lebih semangat dalam menembang. Oleh karena bagi juru sawer yang mudah terpengaruhi oleh suasana, hal ini malahan akan mengurangi semangat dalam menembang. Hal itu juga dapat membuat penembang asal-asalan dalam menembangkan puisi sawer panganten. Sebaliknya, bagi seorang penembang yang tidak mudah terpengaruhi dengan keadaan di sekitarnya, kejadian ini akan dijadikan sebuah tantangan.Tantangan yang harus dilayani dengan mencari cara bagaimana supaya khalayak dapat kembali memerhatikan tembangannya. Salah satu cara yang dilakukan penembang yaitu dengan berpindah lagu atau pupuh. Selain itu melakukan guyonan yang melibatkan khalayak.

Waktu pelaksanaan puisi sawer panganten biasanya pada pagi hari sekitar pukul 10.00 WIB. Waktu tersebut tidak mutlak karena sangat bergantung selesainya acara serah terima dan akad nikah. Sesuai dengan kebiasaan, saweran memang dilaksanakan setelah acara inti dari sebuah pernikahan. Acara inti yang dimaksud, yakni serah terima pengantin laki-laki dan akad nikah. Lamanya tidak dapat ditentukan dengan pasti. Namun, secara umum acara sawer tidak akan lebih dari satu jam. Hal tersebut sangat ditentukan oleh penembang atau juru sawer. Penembang juga dipengaruhi oleh khalayak yang hadir pada waktu itu. Oleh karena ketika penembang/juru sawer sudah melihat reaksi khalayak yang ribut dan tidak lagi memerhatikan penembang, maka pada saat itu sangat diperlukan kreativitas penembang. 
Tempat menembangkan puisi sawer panganten dilakukan di depan atau di halaman rumah. Pada acara tersebut, penembang berada tepat di lawang panto (pintu) atau selain itu di golodog (tangga yang menghubungkan antara teras rumah dengan dalam rumah). Pada saat itu, penembang berdiri menghadap pasangan pengantin dan khalayak. Pengantin membelakangi khalayak atau khalayak berada di belakang pengantin. Jadi, antara penembang, pengantin dan khalayak berhadap-hadapan.

Jarak antara penembang/juru sawer, pengantin dan para hadirin tidak jauh kirakira 2-3 meter. Dari jarak tersebut, terjadi kesan seakan-akan penembang/juru sawer, pengantin dan para hadirin sangat akrab, apalagi antara pengantin dengan para hadirin, seakan menjadi satu bagian.

Cara penyampaian puisi sawer panganten dilakukan secara langsung. Dengan cara, seorang penembang melagukan atau menembangkan dan para pendengar atau khalayak menyimak/mendengarkan. Secara keseluruhan, tembang puisi sawer panganten yang disampaikan oleh juru sawer berisi tentang ajaran Islam. Ajaran yang disampaikan bertemakan tauhid, akhlak, menguraikan tentang suatu hadist/wahyu. Dalam proses penciptaan, untuk menyesuaikan dengan tujuan awal puisi sawer panganten, seorang pencipta setidaknya mengetahui atau menguasai ilmu agama Islam.

Penciptaan dilakukan dalam dua kemungkinan, yaitu: (1) Terjadi secara spontan; (2) Dilakukan dengan cara ditulis terlebih dahulu. Kemungkinan yang pertama, pada situasi spontan, secara mendadak seorang penembang tanpa ada pemberitahuan terlebih dahulu diminta tampil. Teks yang dipakai ada dua kemungkinan, teks yang telah ada dalam ingatan penembang (teks turunan pada umumnya) hasil ciptaan dari leluhur ahli dan teks baru yang terjadi secara spontan. Namun, apabila memakai teks turunan harus disesuaikan dengan tema acara yang diselengggarakan. Apabila tidak sesuai dengan acara, penciptaan teks baru akan terjadi, terjadi secara spontan ketika penembang/juru sawer sedang menembangkan puisi sawer panganten. Tembang mengalir dengan sendirinya. Hal tersebut terjadi karena penembang sudah menguasai formula dari aturan tembang puisi sawer panganten. Hal tersebut sama halnya dengan tembang lainnya, yaitu penguasaan aturan tersebut bukan hasil dari proses penghafalan. Hal itu terjadi dari pengulangan yang terusmenerus.

Kemungkinan yang kedua, penciptaan dengan terlebih dahulu ditulis. Hal tersebut terjadi dalam situasi penembang diundang dengan pemberitahuan terlebih dahulu. Pemberitahuan tersebut terjadi seminggu atau tiga hari sebelum acara dilaksanakan. Penciptaan pada situasi tersebut dilakukan untuk menyesuaikan teks dengan acara yang akan dilaksanakan.

Dalam puisi sawer panganten, seorang pencipta pasti juga merupakan penembang. Akan tetapi, seorang penembang belum tentu dia menciptakan puisi sawer panganten. Oleh karena mungkin saja seseorang hanya mampu menembangkan tanpa bisa menciptakan.

Puisi sawer panganten merupakan sebuah nasihat atau petuah dari orang tua kepada anaknya yang menikah. Tujuan menasihati dalam puisi sawer panganten dapat dikatakan sebagai fungsi pendidikan. Fungsi pendidikan dalam teks puisi sawer panganten yang dijadikan objek penelitian ini, berkaitan dengan masalah keagamaan. Untuk dapat mengetahui kebenarannya dapat diketahui dari bagian isi yang diuraikan penembang dalam puisi sawer panganten.

Secara keseluruhan bagian isi yang diuraikan penembang dalam puisi sawer panganten, merupakan ajaran yang bersumber dari Al-Quran dan hadist. Sebuah hadist yang membicarakan pernikahan yang merupakan salah satu 
cara untuk menyempurnakan agama. Alasan pernikahan disebut sebagai cara menyempurnakan agama, karena dengan menikah, seseorang berarti menjaga agamanya, jiwanya, akalnya, keturunannya, dan hartanya.

Dalam teks puisi sawer panganten, secara jelas disebutkan bahwa tembang tersebut ditujukan bagi kedua pengantin. Akan tetapi, secara implisit, tujuan pencipta menciptakan teks tersebut yaitu untuk semua orang yang mendengarkan. Yang hadir dalam acara tersebut tentu saja beragam, para ibu (istri), bapak (suami), dan remaja putri. Jadi, secara tidak langsung tembang tersebut ditujukan untuk masyarakat luas.

Selain fungsi pendidikan, dalam sawer panganten terdapat juga fungsi hiburan. Dalam teks puisi sawer panganten, terdapat nada-nada dan irama yang tercipta dari tembang tersebut. Dengan mendengar alunan tembang tersebut, pendengar sudah merasa terhibur. Akan tetapi fungsi hiburan yang diperoleh dari teks puisi sawer panganten ini pun tidak berbeda dengan fungsi pendidikan. Fungsi tersebut berlaku hanya untuk mereka yang benar-benar menyimak tembang puisi sawer panganten dan menikmati nada-nadanya. Namun demikian, secara umum, selain prosesi adat, saweran juga merupakan suatu hiburan.

\section{PENUTUP}

Sawer panganten merupakan warisan tradisi budaya Sunda ciptaan masyarakat Sunda secara turun-temurun. Sawer panganten merupakan tradisi pengantar bagi kedua insan yang dipersatukan dalam ikatan pernikahan. Dalam masyarakat Sunda, sawer panganten selalu dilaksanakan dalam seremonial pernikahan. Sawer panganten berisi petatah-petitih (wejangan) kepada kedua mempelai untuk memulai kehidupan dalam rumah tangga sebagai suami istri. Tata nilai dari tradisi sawer panganten sarat dengan pendidikan karakter: ketuhanan (agama), moral, sosial, dan budi pekerti.

Sawer panganten merupakan sebuah tradisi budaya masyarakat Sunda yang kental dan sarat akan nasihat dan doa. Sawer panganten atau yang biasa disebut dengan nyawer adalah upacara memberi nasihat kepada kedua mempelai pasangan pengantin, dilaksanakan setelah acara akad nikah. Nasihat terutama mengamanatkan agar manusia (pengantin) berperilaku baik dalam hubungan kekeluargaan, suami istri, hubungan sosial, teguh pendirian, dan takwa kepada Tuhan Yang Maha Esa.

Puisi sawer umumnya tersusun menjadi tiga bagian yaitu pembukaan, inti, dan penutup. Pembukaan umumnya permohonan maaf kepada Tuhan Yang Maha Esa, Nabi, Wali, leluhur, hadirin untuk melaksanakan acara sawer panganten. Adapun bagian penutup berupa doa untuk keluarga dan hadirin agar mendapatkan keselamatan dan rakhmat dari Tuhan Yang Maha Kuasa. Kedua mempelai duduk berdampingan dengan dinaungi payung, seiring kidung nasihat dilantunkan, sesekali isi bokor di tabur, hadirin yang menyaksikan berebut memunguti uang receh dan permen.

Dari hasil kajian yang dilakukan oleh penulis, dapat disimpulkan bahwa upacara-upacara, baik sebelum acara pernikahan (ngalamar, ngeuyeuk seureuh seserahan) maupun setelah pernikahan (sawer, nincak endog, buka pintu, munduh mantu) masih tetap dilaksanakan oleh masyarakat di Kabupaten Bandung. Kemudian upacara-upacara tersebut masih mempunyai peranan dalam lingkaran hidup masyarakat Sunda, walaupun mungkin sikap anggota masyarakat terhadap pelaksanaan sawer sendiri telah berubah.

Begitu banyak khazanah budaya yang ada di Indonesia ini, khususnya di Jawa Barat, di antaranya yaitu khazanah sastra Sunda. Sayangnya khasanah budaya tersebut sedikit demi sedikit mengalami persaingan yang diakibatkan masuknya budaya asing ke negara kita. Untuk itu 
sudah selayaknyalah sebagai warga negara harus mencintai kebudayaan dan kesenian tanah airnya, baik yang berupa tradisi lisan/bukan tulisan dan tradisi tulis, khususnya tradisi lisan yang ada di Jawa Barat.

Kemudian diadakannya penelitianpenelitian lain terhadap suatu kesenian tradisional seperti di atas sebagai upaya untuk mewariskan karya-karya para leluhur kepada para generasi baru sehingga dapat melestarikan dan mengembangkan khazanah kehidupan sastra Sunda di tengah-tengah persaingan budaya-budaya lain. Sastra klasik merupakan akar budaya bangsa, cermin jati diri bangsa sekaligus merupakan aset bangsa.

Puisi sawer bahasa Sunda yang mengandung nilai budaya perlu dilestarikan dan dikembangkan. Dalam pelestarian dan pengembangannya ditunjang oleh usaha yang sungguhsungguh, bukan saja oleh anggota masyarakat, tetapi juga oleh pemerintah.

\section{DAFTAR SUMBER}

\section{Buku}

Azis, H. A. 2011. Pendidikan Karakter Berpusat pada Hati, Akhlak Mulia Fondasi Membangun Karakter Bangsa. Jakarta: Al-Mawardi.

Danandjaja, James. 2007. Folklor Indonesia. Jakarta : Graffiti Press.

Lembaga Basa \& Sastra Sunda.1975. Kamus Umum Basa Sunda. Bandung:Tarate.

Rusyana, Yus. 1981.

Sastra Lisan Nusantara. Bandung: CV. Dipenogoro.

Rusyana, Yus. 1978.

Sastra Lisan Sunda. Jakarta: Pusat Pembinaan Pengembangan Bahasa Indonesia.

Rusyana.Yus. 1984.

Metode Pengajaran Sastra. Bandung: Gunung Larang.

Semi, M. Atar. 1990.

Metode Penelitian Sastra, Bandung:

Angkasa.
Soekanto, S. 1998.

Sosiologi Suatu Pengantar. Jakarta:

Rajawali.

Rusyana,Yus.1981. Sastra Lisan Nusantara. Bandung: CV.Dipenogoro. $-.1978$.

Sastra Lisan Sunda. Jakarta: Pusat Pembinaan Pengembangan Bahasa Indonesia.

Rusyana, Yus dkk.1988/1989.

Pandangan Hidup Orang Sunda (Seperti

Tercermin dalam Kehidupan

Masyarakat Dewasa Ini) Tahap III.

Bandung: Depdikbud.

Sukatman. 2009.

Butir-butir Tradisi Lisan Indonesia

(Pengantar Teori dan

Pembelajarannya).Yogyakarta :

LaksBang PRESSindo Yogyakarta.

Supendi, Usman. 2006.

Folklore Sunda. Makalah perkuliahan.

Universitas Islam Nusantara Bandung.

Taufiq Hidayat, Rachmat dkk. 2007.

Peperenian Urang Sunda. Bandung: Kiblat Buku Utama.

Warnaen,S.et.al.1987.

Pandangan Hidup Orang Sunda Seperti Tercermin dalam Tradisi Lisan dan Sastra Sunda. Jakarta: Depdikbud.

\section{Internet}

http://pragmatikwacana.blogspot.co.id/2011 /10/berguru-karakter-pada-sawerpanganten.html, diakse 14 Agustus 2015 pukul 11.00 WIB

http://www.kabarpriangan.com/news/detail/ 12570,diakses tanggal10 Agustus 2015 pukul 10.00 WIB.

\section{Sumber Lisan/Informan}

Cucun (53 tahun). 2015.

Seniman Juru Sawer perempuan. Wawancara, Cicalengka 14 Juni 2015

Ujang (48 tahun). 2015.

Seniman Juru Sawer Laki-laki

Wawancara, Cicalengka 14 Juni 2015. 